\title{
GESTÃO DOS RECURSOS HÍDRICOS NO ACRE E A IMPLANTAÇÃO DOS SEUS INSTRUMENTOS
}

\section{WATER RESOURCES MANAGEMENT IN ACRE AND THE IMPLEMENTATION OF ITS INSTRUMENTS}

\author{
Ayri Saraiva Rando \\ Empresa P2A Assessoria Técnica Administrativa - Piracicaba - SP - Brasil \\ Adailton de Sousa Galvão \\ Universidade Federal do Acre - Rio Branco - AC - Brasil
}

\begin{abstract}
Resumo: Este trabalho visa analisar a gestão dos recursos hídricos no Acre, comparando-a com a gestão paulista. Apresentaram-se aspectos da gestão acreana, por meio da análise comparativa pertinente à elaboração e à implantação dos instrumentos previstos nas políticas de recursos hídricos. A metodologia utilizada foi a pesquisa bibliográfica e o levantamento documental, com uso de indicadores propostos para avaliação e monitoramento da dimensão de governança chamada instrumentos de gestão do sistema, em busca do cumprimento da análise em questão e da definição do estágio em que se encontram os aspectos de governança em tal dimensão. Os resultados indicaram que o estágio da gestão é básico para a dimensão de governança avaliada.
\end{abstract}

Palavras-chave: Recursos Hídricos. Governança. Instrumentos de Gestão.

Abstract: This work aims to analyze the management of water resources in Acre, comparing it with the management in the State of São Paulo. Some aspects of management in Acre were presented by comparative analysis of the preparation and implementation of the provided instruments for the water policies. The methodology used was the bibliographical research and documental survey, using proposed indicators for evaluation and monitoring of governance dimension called policy management tools, seeking for the execution of the analysis in question and setting the stage of the governance aspects in this dimension. The results indicated that the management stage is basic to the evaluated governance dimension.

Keywords: Water Resources. Governance. Management Tools.

\section{Introdução}


A gestão dos recursos hídricos no Acre possui suas particularidades, entre as quais: os principais usos destes recursos abastecimento humano, uso na agricultura, navegação, dessedentação de animais, pesca, diluição de efluentes, turismo e uso industrial; a relevância dada à preservação e à conservação dos mesmos para provisão de serviços ambientais; a relevância do uso das vias fluviais para conexão dos municípios acreanos com municípios da Bolívia, do Peru, do Amazonas e de Rondônia; a importância do uso paisagístico e o significado dos rios e igarapés no modo de vida das populações locais; a localização dos municípios às margens dos principais rios; a concentração populacional do estado em sua capital, Rio Branco; e o asfaltamento recente das rodovias BR-364 e BR-317, conectando municípios do Brasil, Peru e Bolívia.

Mesmo com a identificação de problemas de disponibilidade hídrica referentes ao desmatamento e à degradação florestal pelo uso de queimadas, ao uso indiscriminado dos rios para pesca em períodos que não são apropriados, ao uso de agrotóxicos e à destinação de efluentes domésticos; e, apesar das previsões de aumento da intensidade e da frequência de eventos climáticos extremos, do fato das bacias hidrográficas deste estado se localizarem na maior bacia hidrográfica do mundo e de terem características de bacias transfronteiriças internacionais, elas não recebem a atenção merecida no que tange à elaboração e à implantação dos instrumentos de gestão previstos nas políticas de recursos hídricos.

Portanto, entre as dificuldades desta unidade da federação, enfatizam-se as que se relacionam com a implementação dos instrumentos previstos: planos de recursos hídricos, enquadramento dos corpos hídricos, sistema de informações, outorga pelo direito de uso e cobrança pelo uso de recursos hídricos.

Com vistas a superar as dificuldades mencionadas e os desafios relacionados, este trabalho tem o objetivo geral de analisar a gestão dos recursos hídricos no Acre em comparação com a gestão paulista, por meio da análise comparativa sobre a elaboração e implantação dos instrumentos previstos. O objetivo específico é expor um panorama desta gestão, a partir da análise citada. Para tanto, foram utilizados indicadores relativos aos aspectos de governança voltados a uma dimensão, que é denominada instrumentos de gestão do sistema. 


\section{Métodos}

Este artigo utiliza-se da pesquisa bibliográfica e do levantamento documental, sendo a sua área de estudo o próprio Acre, frisando que o Plano Estadual de Recursos Hídricos do Acre - PLERH-AC, para fins de gestão, definiu as seguintes Unidades de Gerenciamento de Recursos Hídricos - UGRHs: UGRH Abunã, a UGRH Acre-Iquiri, a UGRH Purus, a UGRH Envira-Jurupari, a UGRH Tarauacá e a UGRH Juruá. A seguir, o mapa das principais bacias hidrográficas deste estado, ilustrando o caráter de bacias transfronteiriças das mesmas (Figura 1).

Figura 1. Mapa das principais bacias hidrográficas do Acre

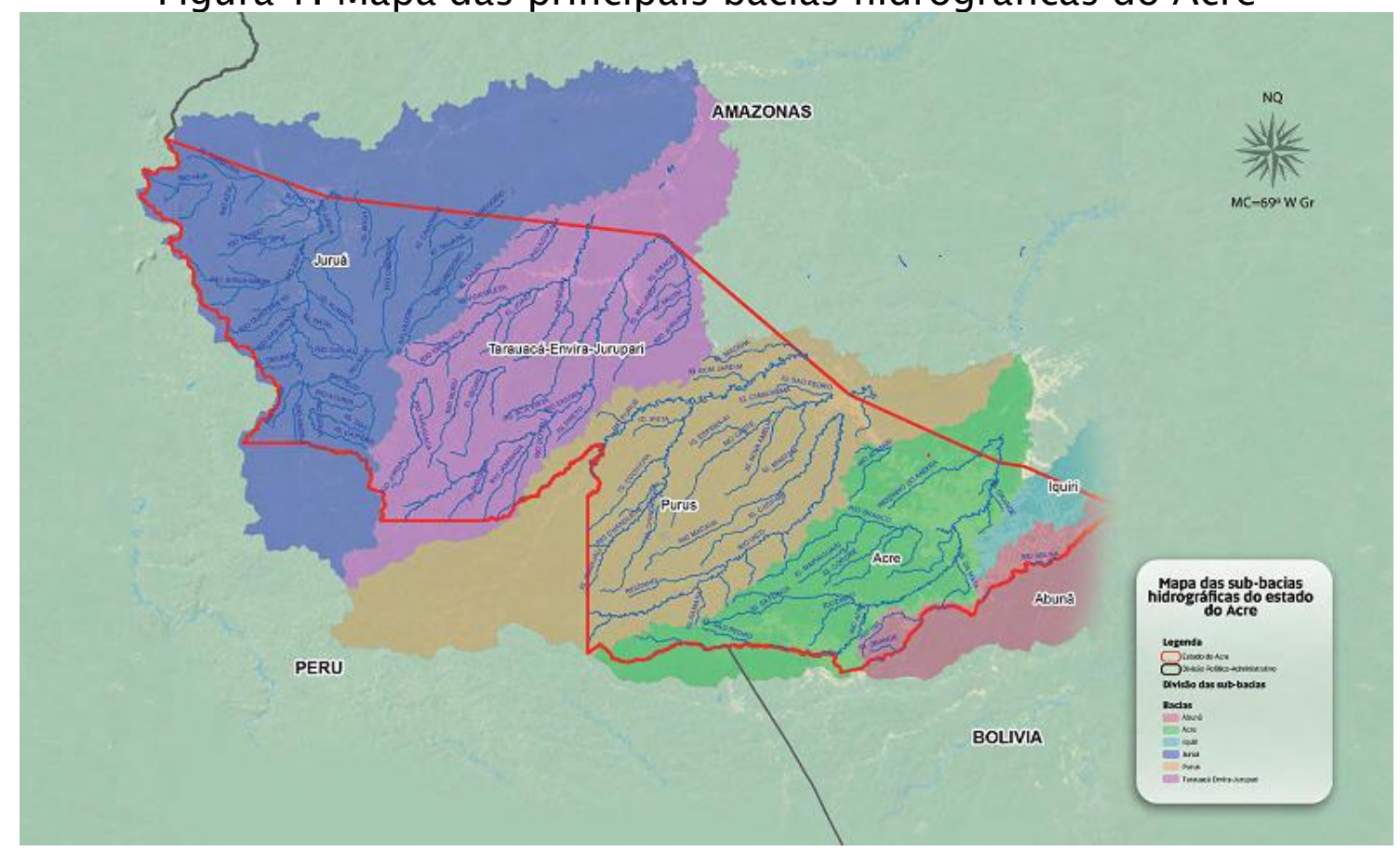

Fonte: SEMA, 2012

As UGRHs correspondem às principais bacias hidrográficas do Acre.

A partir dos trabalhos do World Wide Fund for Nature - WWF Brasil e Fórum Nacional de Comitês de Bacias Hidrográficas (2005), e do WWF Brasil e Fundação Getúlio Vargas - FGV (2014), foi possível fazer a avaliação e comparação pertinentes ao nível de gestão, por meio da análise da elaboração e implantação dos instrumentos de gestão.

$\mathrm{Na}$ dimensão vinculada aos instrumentos de gestão, é importante acompanhar a existência dos planos e relatórios de acompanhamento; a 
clareza na definição da responsabilidade para executar as metas; o dimensionamento do recurso e a definição da sua origem; a existência de um sistema de monitoramento, com definição de ente responsável e com definição de periodicidade; e a disponibilidade de recursos financeiros (WWF BRASIL; FGV, 2014).

Portanto, uma alternativa para analisar tal dimensão seria coletar dados conforme detalhamentos expostos a seguir (Quadro 1).

Quadro 1. Indicadores e verificadores para acompanhamento dos instrumentos de gestão

\begin{tabular}{|c|c|c|c|c|}
\hline $\begin{array}{c}\text { Dimensão } \\
\text { da } \\
\text { Governança }\end{array}$ & $\begin{array}{l}\text { Aspectos da } \\
\text { Governança }\end{array}$ & $\begin{array}{l}\text { O que pretende } \\
\text { verificar }\end{array}$ & Indicadores & Fontes \\
\hline \multirow{4}{*}{ 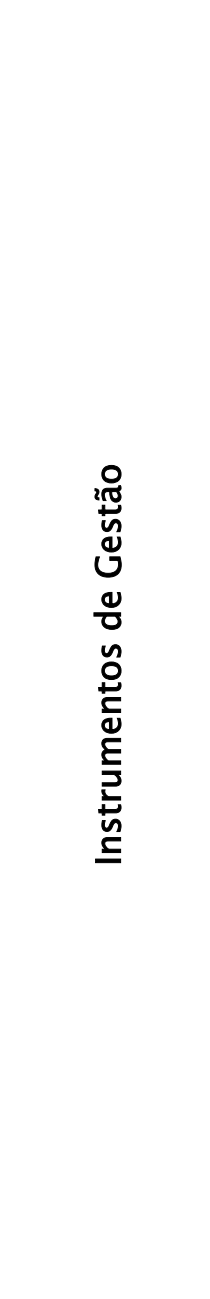 } & 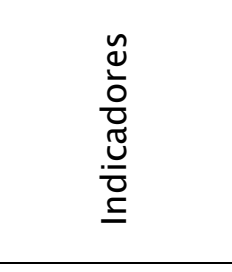 & $\begin{array}{l}\text { A existência de } \\
\text { indicadores que } \\
\text { auxiliem no } \\
\text { monitoramento } \\
\text { das ações }\end{array}$ & $\begin{array}{l}\text { Disponibilizaçã } \\
0 \quad \text { dos } \\
\text { indicadores no } \\
\text { planejamento }\end{array}$ & \multirow{4}{*}{$\begin{array}{l}\text { Análise de } \\
\text { documentos: } \\
\text { Planos e } \\
\text { Relatórios de } \\
\text { Acompanham } \\
\text { ento dos } \\
\text { planos } \\
\text { existentes }\end{array}$} \\
\hline & 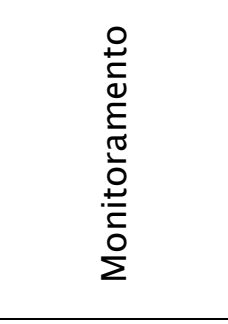 & $\begin{array}{l}\text { A existência e a } \\
\text { periodicidade } \\
\text { do } \\
\text { monitoramento }\end{array}$ & $\begin{array}{l}\% \text { de ações de } \\
\text { monitorament } \\
\text { o executada } \\
\text { em um período } \\
\text { pré- } \\
\text { determinado }\end{array}$ & \\
\hline & 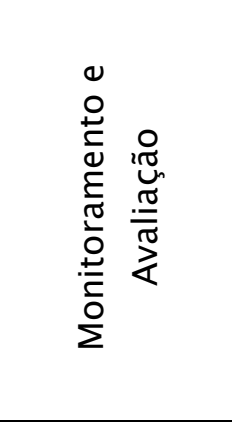 & $\begin{array}{l}\text { A efetividade do } \\
\text { monitoramento, } \\
\text { ou seja, se as } \\
\text { necessidades de } \\
\text { correção } \\
\text { constatadas são } \\
\text { incorporadas ao } \\
\text { planejamento }\end{array}$ & $\begin{array}{l}\% \text { de } \\
\text { recomendaçõe } \\
\text { s resultantes } \\
\text { de avaliação } \\
\text { incorporada ao } \\
\text { planejamento }\end{array}$ & \\
\hline & 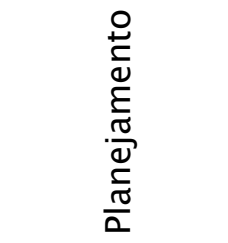 & $\begin{array}{l}\text { A execução do } \\
\text { planejamento }\end{array}$ & $\begin{array}{l}\text { Metas } \\
\text { implementada } \\
\text { s / Metas } \\
\text { previstas }\end{array}$ & \\
\hline
\end{tabular}

Fonte: WWF Brasil e FGV, 2014.

Devido às diferenças acentuadas no nível de implementação dos instrumentos de gestão na política acreana e na política paulista, 
identificando que o Acre ainda não elaborou e publicou seu relatório de acompanhamento do plano estadual, a verificação da execução do planejamento fica impossibilitada devido à inexistência da fonte de tal verificação.

Assim, a análise da dimensão referente aos instrumentos em questão é feita em um quadro comparativo entre essas políticas, apontando a fase de elaboração e/ou implantação dos instrumentos previstos nas mesmas, tais como: planos, enquadramento, sistema de informações, outorga, cobrança e operacionalização do fundo estadual; além do uso de indicadores, como a existência de cadastro atualizado de usuários disponível ao público e a existência da cobrança pelo uso dos recursos hídricos para o acompanhamento da dimensão pertinente aos instrumentos mencionados.

A existência e a disponibilidade de tal cadastro ao público são indicadores que visam expressar a existência e o acesso ao cadastro citado, tendo como fonte de verificação o próprio órgão gestor (WWF BRASIL; FÓRUM NACIONAL DE COMITÊS DE BACIAS HIDROGRÁFICAS, 2005). Segundo a Agência Nacional de Águas - ANA (2013), a cobrança pelo uso dos recursos hídricos é um indicador do estágio da implementação da política de recursos hídricos, porque a sua implantação depende da concretização de outros instrumentos da mesma. Portanto, enfatiza-se que tais indicadores também foram usados na análise desta dimensão.

A bibliografia consultada incluiu a Conjuntura dos Recursos Hídricos no Brasil 2013, Planos Estaduais de Recursos Hídricos de São Paulo e do Acre, resumo do Relatório Paulista de Situação dos Recursos Hídricos, e as deliberações e resoluções dos colegiados que integram os respectivos sistemas estaduais de gerenciamento. Os indicadores são resultados do processo de discussão para criação do Observatório das Águas no Brasil, o qual tem a finalidade de monitorar a governança do Sistema Nacional de Gerenciamento de Recursos Hídricos - SINGREH.

O WWF Brasil e a FGV uniram-se para realizar estudo, o qual propôs alguns indicadores e bases para a constituição de uma sistemática de monitoramento do SINGREH, a partir da elaboração de um termômetro da situação dos principais aspectos de governança, que registra estágio básico, intermediário ou avançado. Portanto, os indicadores a serem utilizados no mesmo referem-se ao WWF Brasil e 
Fórum Nacional de Comitês de Bacias Hidrográficas (2005), e ao WWF Brasil e FGV (2014).

O modelo de governança pública proposto por Abrucio et al. (2011 apud WWF BRASIL; FGV, 2014) aborda cinco dimensões: ambiente institucional; capacidades estatais; instrumento de gestão do sistema; relações intergovernamentais; interação do estado com a sociedade. $\mathrm{O}$ trabalho em pauta abordou a análise de apenas uma dimensão de governança - instrumentos de gestão do sistema. Para identificar em que ponto está a política de recursos hídricos na dimensão em análise, utilizou-se o termômetro produzido por WWF Brasil e FGV (2014). 


\section{Governança}

A partir da Constituição federal de 1988, a sociedade brasileira vem se reformulando e tem sido objeto de processos descentralizadores e de criação de arranjos institucionais participativos. Desde então, direitos e poderes têm sido essenciais à descentralização, dando oportunidade ao exercício de modos compartilhados de gestão (TENÓRIO, 2011).

Cymbalista et al. (2008) reforçaram que, a partir dos anos 1990, a sociedade civil tem atuado pela concretização dos princípios estabelecidos nesta Constituição ao participar da concepção e implantação de novas políticas públicas, estando entre tais princípios: a criação de conselhos gestores com participação direta da população, a consolidação dos sistemas de políticas públicas e a aprovação de legislação específica para as diferentes áreas das políticas sociais.

A consolidação da democracia reforça o controle e a avaliação do impacto de políticas públicas, que demandam das Organizações Não Governamentais - ONGs e dos movimentos sociais um conhecimento qualificado e detalhado do processo de construção e monitoramento destas políticas (CYMBALISTA et al., 2008).

Assim, a perspectiva de controle social ampliado é resultado da atuação autônoma e qualificada das organizações da sociedade civil, cuja atuação constitui um processo de construção coletiva de projetos de sociedade e de propostas de políticas públicas. Portanto, o controle social está vinculado diretamente com a participação, sendo que a confirmação da perspectiva de controle social ampliado engloba a transparência e acesso à informação sobre as políticas e ações públicas, o monitoramento e a possibilidade de acompanhamento sistemático da execução de ações, e a participação social na definição e no desenvolvimento das mesmas (SERAFIM, 2007).

Ao abordar instrumentos de gestão das políticas de recursos hídricos no Brasil, o termo governança ganha notoriedade. Robles et. al. (2011) frisaram que o termo governança começou a ser usado nos finais dos anos 1980 e no início dos anos 1990, definindo governança como um processo de tomada de decisões que se exerce em conjunto com vários atores públicos e privados envolvidos na gestão de políticas públicas, ou seja, as estratégias de governo se enfatizam nas 
necessidades da sociedade e em uma participação mais direta da mesma nas decisões que the interessem.

Já Dallabrida (2011) destacou o conceito de governança territorial para se referir às ações que expressam a capacidade de uma sociedade organizada territorialmente para gerir os assuntos públicos a partir do desenvolvimento conjunto e cooperativo dos atores sociais, econômicos e institucionais.

Especificamente, tratando-se da governança hídrica, a necessidade de dividir as águas compartilhadas pelos estados e protegê-las chamou a atenção para o fato de que o risco de crise hídrica e de conflitos não eram causados geralmente pela escassez da água, mas, principalmente, por problemas relacionados à governança das águas (VILLAR, 2013). 
A diferença entre governança da água e gestão da água é que a governança é o conjunto de processos e instituições que definem e identificam quais são as metas de gestão a serem perseguidas. A gestão trata dos mecanismos e medidas práticas utilizadas para atingirem as metas traçadas e, portanto, atingir melhores resultados. Assim, a governança da água fornece a estrutura para decidir quais serão as atividades de gestão dos recursos hídricos que serão implementadas, podendo mencionar que uma crise da governança hídrica é uma crise nos processos de tomada de decisão e das instituições (LAUTZE, 2011 apud SANT'ANNA, 2012).

Ressalta-se que este artigo analisou a dimensão dos instrumentos de gestão do sistema, utilizando-se o modelo de governança pública proposto por Abrucio et al. (2011 apud WWF BRASIL; FGV, 2014).

\subsection{Gestão dos Recursos Hídricos no Brasil}

A disponibilidade hídrica envolve aspectos quantitativos e qualitativos da água. Inclui também a distribuição não homogênea de água doce no mundo, as diferentes distribuições da população humana nas regiões de terra firme e o ciclo hidrológico. Enfatiza-se, então, que existe água em grande quantidade no planeta, o que não significa que ela esteja disponível aos diversos usos que a sociedade faz deste recurso, os denominados usos múltiplos (ANA, 2012).

Tucci e Mendes (2006) destacaram que o uso do recurso hídrico refere-se ao atendimento das atividades humanas que dependem de água e às necessidades dos animais, peixes, plantas, microrganismos, entre outros.

Segundo SEMA (2012), a região hidrográfica amazônica representa aproximadamente $40 \%$ do território brasileiro, além de deter cerca de $60 \%$ de toda a disponibilidade hídrica do país.

O Acre situa-se na região hidrográfica citada, onde a ocorrência de eventos climáticos extremos também merece destaque, demandando a gestão adequada dos recursos hídricos.

O termo bacia hidrográfica já apareceu algumas vezes no texto, cabendo, então, a apresentação do seu conceito. Em cada seção de um rio existirá uma bacia hidrográfica, assim, a bacia é toda a área que contribui por gravidade para os rios até chegar à seção que define e que 
é delimitada pela topografia da superfície. As características principais da bacia são a área de drenagem, o comprimento do rio principal, declividade do rio e a declividade da bacia (TUCCI; MENDES, 2006).

Tratando-se do aspecto legal da gestão dos recursos hídricos, a política nacional prevê a implementação de instrumentos de gestão e de sistema de gerenciamento. Os instrumentos dessa política são os planos de recursos hídricos; o enquadramento dos corpos de água em classes, segundo seus usos preponderantes; a outorga dos direitos de uso de recursos hídricos; a cobrança pelo uso desses recursos; e o sistema de informações sobre tais recursos (BRASIL, 1997).

Os planos de recursos hídricos, segundo Setti et al. (2000), são documentos programáticos para o setor no espaço de cada bacia, procurando-se definir a repartição das vazões entre os usuários, além de serem instrumentos de planejamento que orientam a sociedade e a atuação dos gestores em relação ao uso, recuperação, proteção, conservação e desenvolvimento dos recursos hídricos.

Os planos em pauta devem ser elaborados em três níveis: federal, estadual ou distrital e no âmbito da bacia hidrográfica.

O enquadramento dos corpos de água em classes de uso é outro instrumento de gestão, o qual permite fazer a ligação entre a gestão da quantidade e a gestão da qualidade da água, possibilitando o estabelecimento de um sistema de vigilância sobre os níveis de qualidade da água dos mananciais (SETTI et al., 2000).

$O$ objetivo de tal instrumento é assegurar às águas qualidade compatível com os usos mais exigentes a que forem destinadas (ANA, $2011 b)$.

O enquadramento e os planos de recursos hídricos são os instrumentos destinados ao planejamento e que servem de referência para outros dois instrumentos: outorga e cobrança. A elaboração destes planos e do enquadramento demanda bases técnicas confiáveis e representativas, portanto, este instrumento possui uma relação direta e de dependência do sistema de informações estruturado. Outro fator relevante é que a outorga para diluição de efluentes deve ser emitida com observância das classes de qualidade, padrões e limites considerados no enquadramento do corpo hídrico (ANA, $2011 \mathrm{~b}$ ).

Assim, a geração de dados e a implementação do sistema de informações é fundamental para a implantação dos instrumentos de 
gestão em uma ordem lógica e adequada à gestão dos recursos em questão.

Conforme a ANA (2013), é facultado às unidades da federação o uso do Cadastro Nacional de Usuários de Recursos Hídricos - CNARH como cadastro estadual/distrital e acessar os dados de sua unidade diretamente no banco de dados desta agência ou desenvolver seu próprio módulo de cadastro e optar por um procedimento de sincronismo entre bancos de dados estadual/distrital.

Já a outorga é o instrumento que tem o objetivo de assegurar o controle quantitativo e qualitativo dos usos da água, garantindo ao usuário outorgado o direito de acesso à água ao regularizar o seu uso em uma bacia hidrográfica (BRASIL, 1997).

Outorga pode ser definida como um instrumento pelo qual o usuário recebe autorização, concessão ou permissão para fazer uso da água, constituindo-se no elemento central do controle para o uso racional dos recursos hídricos (SETTI et al., 2000). Portanto, a outorga depende diretamente do cadastro de usos e de usuários na bacia hidrográfica para o controle efetivo dos usos múltiplos e para identificação dos conflitos existentes e potenciais.

Segundo a ANA (2013), a cobrança não é um imposto, mas uma remuneração pelo uso de um bem público, cuja receita é uma renda patrimonial, ou da União ou do Estado, sob qual está o domínio da água. Isso é, o usuário, ao optar voluntariamente em fazer uso de um bem público, realiza uma compensação à sociedade. 
2.2 Instrumentos de Gestão dos Recursos Hídricos no Estado de São Paulo

A Lei Estadual No 7.663, de 30 de dezembro de 1991, instituiu a Política Estadual de Recursos Hídricos de São Paulo e criou o seu Sistema Integrado de Gerenciamento de Recursos Hídricos - SIGRH. A mesma está pautada nos fundamentos e instrumentos da política nacional, bem como em estruturação semelhante ao sistema de gerenciamento.

Conforme São Paulo (2014), a estrutura da rede hidrográfica paulista está dividida em 7 regiões hidrográficas e 22 Unidades Hidrográficas de Gerenciamento de Recursos Hídricos - UGRHI.

\subsubsection{Planos de Recursos Hídricos}

Segundo a ANA (2013), o Plano Estadual de Recursos Hídricos de São Paulo - PERH foi concluído até 2009. Destacou-se, também, que existem planos de bacias em todas as unidades de domínio estadual.

O primeiro PERH foi elaborado em 1990 e se encontra em sua sexta atualização para o quadriênio 2012-2015.

A estruturação das proposições e compromissos institucionais que se constituem no PERH 2012-2015 foi apresentada em cinco áreas temáticas. Os resultados desses compromissos assumidos foram expostos para cada uma de tais áreas temáticas, para componentes estratégicos, componentes prioritários e componentes específicos, sendo que, para cada componente específico, foram identificados os executores, as metas - prazo e quantidade, os indicadores de acompanhamento e os recursos financeiros estimados (SÃO PAULO, 2014).

Frisa-se que há relatório de acompanhamento do PERH 20122015, que é o relatório de situação correspondente ao período abordado. Portanto, o relatório de situação dos recursos hídricos no Estado de São Paulo é um instrumento de avaliação e monitoramento da gestão das águas.

\subsubsection{Enquadramento dos Corpos Hídricos}


No Brasil, segundo a ANA (2011b), existiam alguns exemplos de ações de enquadramento em bacias interestaduais, entre elas, a experiência de elaboração de propostas e diretrizes de enquadramento de corpos d'água para as bacias dos Rios Piracicaba, Capivari e Jundiaí PCJ.

Foi frisado que, em 2012, no Estado de São Paulo, continuaram as discussões sobre as ações necessárias para a implementação do enquadramento nas Bacias PCJ, o qual foi definido pelo Plano de Bacia 2010-2020 e aprovado pelos Comitês PCJ (ANA, 2013).

São Paulo (2014) reforçou que a UGRHI 05 - PCJ apresentou, em seu plano das bacias hidrográficas dos Rios PCJ para o período de 2010 a 2020, a proposição de atualização do enquadramento dos cursos d'água destas bacias, a ser efetivado até 2035, o qual aguarda manifestação do Conselho Nacional de Recursos Hídricos - CNRH para ser validado. Destacou-se, também, que o enquadramento estabelecido pelo Decreto Estadual $N^{\circ} 10.755 / 1977$ continua vigente. 


\subsubsection{Sistema de Informações}

Nitidamente, existem desigualdades regionais na densidade de estações pluviométricas e fluviométricas em operação no país, sendo que as menores densidades foram encontradas na Região Norte e parte da Região Centro-Oeste (ANA, 2013).

\subsubsection{Outorga pelo Direito de Uso dos Recursos Hídricos}

Todos os estados têm leis com previsão para a emissão de outorgas, porém, nem todos aplicam o instrumento em pauta, o que expõe os variados estágios de implementação no país (ANA, 2011 a).

Segundo a ANA (2013) e devido à publicação da Resolução Conselho Nacional de Recursos Hídricos - CNRH N¹26/2011, passou a ser obrigatória a integração das bases de dados dos sistemas estaduais de cadastro de usuários de recursos hídricos com o CNARH.

As bacias dos Rios PCJ possuem CNARH integral. Já as demais bacias do Estado de São Paulo não utilizam tal cadastro. Porém, ressaltou-se que no Estado de São Paulo há cadastro de usuários nas bacias de domínio do estado devido ao estabelecimento da cobrança (ANA, 2013).

Continuando nessa unidade da federação, os compromissos relacionados à outorga pelo direito de uso de recursos hídricos tiveram avanços superiores à média geral de implementação das metas do plano estadual (SÃO PAULO, 2014).

\subsubsection{Cobrança pelo Uso dos Recursos Hídricos}

Conforme a ANA (2013), atualmente, encontra-se implantada a cobrança nas águas de domínio da União das bacias hidrográficas do Rio Paraíba do Sul, dos Rios PCJ, do Rio São Francisco e do Rio Doce. No âmbito das águas de domínio dos estados, em São Paulo, a cobrança já foi implementada nas bacias PCJ, na bacia do Paraíba do Sul, na bacia do Sorocaba - Médio Tietê e na bacia da Baixada Santista. Isso significa que a cobrança está em andamento em 4 das 22 UGRHI paulistas. 
Ainda na esfera paulista, as UGRHIs encontram-se em diferentes etapas de implantação da cobrança, ou seja, seis UGRHIs já realizam a cobrança via boletos emitidos, oito possuem este instrumento autorizado pelo Governador por meio de Decreto Estadual e estão em trâmites administrativos para operacionalizá-la, quatro UGRHIs têm a cobrança aprovada pelo $\mathrm{CRH}$ e aguardam manifestação do poder executivo, e as outras quatro estão em fases anteriores da implantação deste instrumento de gestão (SÃO PAULO, 2014). 


\subsubsection{Fundo}

O Fundo Estadual de Recursos Hídricos de São Paulo - FEHIDRO foi criado para dar suporte financeiro à política estadual e respectivas ações (SÃO PAULO, 1991). Observa-se que as fontes de recursos são diversas e existem critérios de distribuição dos recursos financeiros entre as UGRHIs aprovados pela Deliberação CRH N 147/2012.

\subsection{Instrumentos de Gestão dos Recursos Hídricos no Acre}

O Estado do Acre é o mais ocidental dos estados da Amazônia brasileira. Sua área é de aproximadamente $160 \mathrm{mil} \mathrm{km}^{2}$, equivale a menos de $2 \%$ do total do país e sua população foi estimada em 733.559 habitantes, em 2010. Tal estado faz fronteira com Bolívia e Peru e duas unidades da federação, Amazonas e Rondônia, e mantém cerca de 85\% de sua área florestal preservada (SEPLAN, 2011).

A Lei Estadual No 1.500 de 2003 instituiu a Política Estadual de Recursos Hídricos e criou o Sistema Estadual de Gerenciamento de Recursos Hídricos do Estado do Acre. Essa política baseia-se nos mesmos fundamentos e instrumentos da política nacional, assim como, praticamente, na mesma estruturação do seu sistema de gerenciamento.

O Acre é a única unidade da federação que não possui conselho estadual de recursos hídricos (ANA, 2013). No entanto, existe fórum de discussão sobre o tema, que é a Câmara Técnica de Recursos Hídricos CTRH, criada no âmbito do Conselho Estadual de Meio Ambiente, Ciência e Tecnologia - CEMACT, pertencente ao Sistema Estadual de Meio Ambiente, Ciência e Tecnologia - SISTEMACT.

\subsubsection{Planos de Recursos Hídricos}

Segundo a ANA (2013), o PERH do Acre foi concluído em 2011. Tal plano possui quatro diretrizes e prevê dez programas (SEMA, 2012).

Visando o gerenciamento da implementação do PLERH-AC, foi criada a Comissão Permanente de Acompanhamento, Monitoramento e Avaliação - CMAI junto ao Departamento de Gestão de Recursos Hídricos e Qualidade Ambiental da SEMA. A estruturação de um Sistema 
de Gerenciamento da Implantação do Plano, de seus Programas e Projetos - SIGI está prevista no plano em questão. Nesse sentido, para os projetos do plano citado, foi proposto um conjunto de 46 indicadores para constituição do Banco de Dados Integrados de Informações - BDI do SIGI e para subsídio ao Sistema de Informações para Monitoramento e Gestão Integrada dos Recursos Hídricos do Acre - SIRENA (SEMA, 2012).

Ainda para a SEMA (2012), a previsão da implantação dos planos de bacia hidrográfica dos rios e igarapés do Acre encontra-se no detalhamento dos projetos do PLERH, diretriz I pertinente à implementação da política de gestão integrada dos recursos hídricos no estado, programa 1 que aborda da implementação dos instrumentos de gestão dos recursos hídricos, como projeto 1.4. 


\subsubsection{Enquadramento dos Corpos Hídricos}

A SEMA (2012) ressaltou a previsão da implantação do enquadramento no detalhamento dos projetos do PLERH-AC, diretriz I relativa à implementação da política de gestão integrada dos recursos hídricos neste estado, programa 1, que trata da implementação dos instrumentos de gestão dos recursos hídricos, como projeto 1.3.

\subsubsection{Sistema de Informações}

$\mathrm{Na}$ esfera de órgãos estaduais, a região amazônica não apresenta rede de monitoramento de qualidade da água, exceto a operada pela ANA, que mede apenas quatro parâmetros e uma operada por órgão ambiental do Mato Grosso, na bacia do Rio Tapajós. No Acre, identificaram-se oito estações desse tipo nas suas bacias hidrográficas (ANA, 2013).

A SEMA (2012) citou que existem 23 estações pluviométricas na área de abrangência do PLERH-AC, porém, na análise que originou este plano, foi considerada uma área maior na qual existem 26 estações. Enfatizou-se também que a rede de estações fluviométricas da ANA no Acre mede cota e vazão.

Destaca-se que houve crescimento recente no número de estações, que é a base para a geração de dados e implementação do SIRENA.

Segundo a SEMA (2012), esse sistema de informações tem o objetivo principal de reunir as informações existentes, formatar um banco de dados georreferenciados e organizados por UGRH, a partir da Base Cartográfica Digital da Fundação Tecnológica do Estado do Acre FUNTAC. Tal sistema deve ser estruturado e desenvolvido de forma compatibilizada com o Sistema Nacional de Informações sobre Recursos Hídricos - SNIRH da ANA, bem como com os sistemas dos estados do Amazonas e de Rondônia.

Ainda de acordo com a SEMA (2012), está prevista a implantação do SIRENA no detalhamento dos projetos do PLERH-AC, diretriz I referente à implementação da política de gestão integrada dos recursos 
hídricos no estado, programa 1 , que engloba a implementação dos instrumentos de gestão dos recursos hídricos, como projeto 1.1.

No programa 2 da diretriz I, pertinente à implantação da rede de monitoramento quali-quantitativo das águas superficiais e subterrâneas do estado, estão previstos o projeto da Rede de Monitoramento Qualiquantitativo das Águas Surperficiais do Acre, o projeto sobre os Estudos Técnicos visando a Implantação da Rede de Monitoramento da Qualidade das Águas Subterrâneas e o projeto de Implantação do Monitoramento da Qualidade das Águas e da Sanidade Animal em Corpos Hídricos utilizados para Piscicultura no Acre, ou seja, os projetos 2.1, 2.2 e 2.3, respectivamente (SEMA, 2012). 


\subsubsection{Outorga pelo Direito de Uso dos Recursos Hídricos}

Conforme abordado na situação do cadastro estadual de usuários e da utilização do CNARH, citada pela ANA (2013), o Acre não utiliza este cadastro, portanto, deve ter um cadastro próprio. Além disso, ao consultar as resoluções do CEMACT disponíveis ao público, não foram encontrados encaminhamentos relativos ao assunto.

A SEMA (2012) enfatizou que está prevista a implantação do Sistema de Outorga dos Recursos Hídricos do Acre, no detalhamento dos projetos do PLERH, diretriz I relacionada à implementação da política de gestão integrada dos recursos hídricos no Estado, programa 1, que trata da implementação dos instrumentos de gestão dos recursos hídricos, como projeto 1.2.

\subsubsection{Cobrança pelo Uso dos Recursos Hídricos}

No Acre não tem bacia hidrográfica com cobrança estabelecida junto ao setor hidrelétrico. Frisa-se, ainda, que não há cobrança pelo uso dos recursos hídricos em mananciais de domínio da União e do estado.

Para a SEMA (2012), está prevista a implantação dos estudos para aplicação de instrumentos econômicos à gestão de recursos hídricos no estado, no detalhamento dos projetos do PLERH-AC, diretriz I voltada à implementação da política de gestão integrada dos recursos hídricos no mesmo, programa 1, que vincula-se à implementação dos instrumentos de gestão de tais recursos, como projeto 1.6.

\subsubsection{Fundo}

O Fundo Especial de Meio Ambiente para Recursos Hídricos do Acre - FEMAC foi criado pela Lei $N^{0} 1.117$ de 1994. Esse fundo é gerenciado pelo Instituto de Meio Ambiente do Acre - IMAC para execução da política estadual de meio ambiente. Acre (1994) destacou que o quadro demonstrativo das origens e aplicações dos recursos do fundo citado deve ser publicado semestralmente no Diário Oficial do Estado e em periódico local de grande circulação. 


\section{Resultados e discussões}

A análise da gestão acreana e a comparação dela com a gestão paulista estão na sequência (Quadro 2). 


\section{Quadro 2. Comparativo das políticas paulista e acreana em relação à} elaboração e implantação dos instrumentos de gestão

\begin{tabular}{|c|c|c|c|c|}
\hline Instrumentos & $\begin{array}{l}\text { Fase Atual na Política } \\
\text { Paulista }\end{array}$ & $\begin{array}{c}\text { Fase Atual na } \\
\text { Política } \\
\text { Acreana }\end{array}$ & $\begin{array}{c}\text { Termômetr } \\
\text { o na } \\
\text { Gestão } \\
\text { Acreana }\end{array}$ & Comentários \\
\hline Plano Estadual & $\begin{array}{l}\text { Existência do PERH } 2012- \\
2015 \text {, aprovado em } \\
\text { dezembro de } 2011 \text {, que é } \\
\text { o sexto plano. }\end{array}$ & $\begin{array}{l}\text { Seu primeiro } \\
\text { plano foi } \\
\text { concluído em } \\
2011 .\end{array}$ & $\begin{array}{l}\text { Estágio } \\
\text { Intermediár } \\
\text { io }\end{array}$ & $\begin{array}{l}\text { Existência dos relatórios } \\
\text { de situação de recursos } \\
\text { hídricos do estado de SP, } \\
\text { isto é, tal estado possui } \\
\text { ferramenta de avaliação e } \\
\text { monitoramento. }\end{array}$ \\
\hline $\begin{array}{l}\text { Planos de } \\
\text { Bacias }\end{array}$ & $\begin{array}{l}\text { Todos os planos de bacia } \\
\text { de domínio estadual foram } \\
\text { concluídos até } 2009 \text {. }\end{array}$ & $\begin{array}{l}\text { Não há planos } \\
\text { de bacia. } \\
\text { Existem } \\
\text { mobilizações, } \\
\text { articulações e } \\
\text { estudos nesta } \\
\text { esfera por } \\
\text { bacia. }\end{array}$ & $\begin{array}{l}\text { Estágio } \\
\text { Básico }\end{array}$ & $\begin{array}{l}\text { Em SP, os planos de } \\
\text { bacias interestaduais } \\
\text { foram elaborados ou } \\
\text { estavam em elaboração. }\end{array}$ \\
\hline $\begin{array}{c}\text { Enquadrament } \\
\text { o }\end{array}$ & $\begin{array}{l}\text { Atualização do } \\
\text { enquadramento nas bacias } \\
\text { PCJ, apresentado em } 2014 \text {. } \\
\text { A bacia do Tietê também } \\
\text { tem iniciativa. }\end{array}$ & $\begin{array}{l}\text { Não há } \\
\text { iniciativas de } \\
\text { enquadrament } \\
\text { o }\end{array}$ & $\begin{array}{l}\text { Estágio } \\
\text { Básico }\end{array}$ & $\begin{array}{lr}\text { O PLERH-AC } & \text { prevê } \\
\text { implementação } & \text { do } \\
\text { enquadramento } & \text { no } \\
\text { projeto } 1.3 . & \end{array}$ \\
\hline $\begin{array}{l}\text { Sistema de } \\
\text { Informações }\end{array}$ & $\begin{array}{l}\text { Os relatórios de situação } \\
\text { dos recursos hídricos são } \\
\text { produzidos periodicamente } \\
\text { desde } 2007 \text { pelas } \\
\text { secretarias } \\
\text { executivas de todos os } \\
\text { CBHs, com roteiro pré- } \\
\text { estabelecido e rol de } \\
\text { parâmetros para o Banco } \\
\text { de Indicadores. }\end{array}$ & $\begin{array}{l}\text { - } 8 \text { estações } \\
\text { de } \\
\text { monitorament } \\
\text { o da qualidade } \\
\text { da água, } \\
\text { operadas pela } \\
\text { ANA, até } 2011 \\
\text { - } 19 \text { estações } \\
\text { fluviométricas, } \\
\text { até } 2012 \\
\text { - } 23 \text { estações } \\
\text { pluviométricas } \\
\text {, até } 2012\end{array}$ & $\begin{array}{l}\text { Estágio } \\
\text { Básico }\end{array}$ & $\begin{array}{l}\text { O PLERH-AC prevê a } \\
\text { implantação do SIRENA } \\
\text { no projeto } 1.1 \text {. }\end{array}$ \\
\hline $\begin{array}{l}\text { Outorga do } \\
\text { Direito de Uso }\end{array}$ & $\begin{array}{l}\text { As bacias PCJ possuem } \\
\text { CNARH integral. As demais } \\
\text { bacias não utilizam este } \\
\text { tipo de cadastro, porém, o } \\
\text { cadastro avançou nas } \\
\text { bacias de domínio do } \\
\text { estado devido ao } \\
\text { estabelecimento } \\
\text { cobrança. }\end{array}$ & $\begin{array}{l}\text { O cadastro de } \\
\text { usuários } \\
\text { encontra-se } \\
\text { em construção }\end{array}$ & $\begin{array}{l}\text { Estágio } \\
\text { Básico }\end{array}$ & $\begin{array}{l}\text { O PLERH-AC prevê a } \\
\text { implantação do sistema } \\
\text { de outorga do direito de } \\
\text { uso dos recursos hídricos } \\
\text { no projeto } 1.2 \text {. }\end{array}$ \\
\hline $\begin{array}{c}\text { Cobrança pelo } \\
\text { Uso }\end{array}$ & $\begin{array}{l}\text { - A cobrança nas águas de } \\
\text { domínio da União foi } \\
\text { implantada nas bacias do } \\
\text { Paraíba do Sul e do PCJ } \\
\text { - Para as águas de domínio }\end{array}$ & $\begin{array}{l}\text { Não há } \\
\text { experiência de } \\
\text { cobrança e } \\
\text { não existem } \\
\text { estudos }\end{array}$ & $\begin{array}{l}\text { Estágio } \\
\text { Básico }\end{array}$ & $\begin{array}{l}\text { O PLERH-AC prevê a } \\
\text { realização de estudos até } \\
2014 \text { e a cobrança } \\
\text { pelo uso dos recursos } \\
\text { hídricos implantada }\end{array}$ \\
\hline
\end{tabular}




\begin{tabular}{|c|c|c|c|c|}
\hline & $\begin{array}{l}\text { estadual, do total de } 22 \\
\text { UGRHIs, } 6 \text { já realizam a } \\
\text { cobrança via boletos } \\
\text { emitidos, } 8 \text { possuem este } \\
\text { instrumento autorizado via } \\
\text { Decreto Estadual, } 4 \text { UGRHIs } \\
\text { têm a cobrança aprovada } \\
\text { pelo CRH e aguardam } \\
\text { manifestação do poder } \\
\text { executivo, e as outras } 4 \\
\text { estão em fases anteriores } \\
\text { de implantação. }\end{array}$ & $\begin{array}{ll}\text { realizados } & \text { ou } \\
\text { acessíveis ao } & \text { á } \\
\text { público até } \\
2014\end{array}$ & & até 2020 , no projeto 1.6 \\
\hline $\begin{array}{l}\text { Fundo } \\
\text { Estadual }\end{array}$ & $\begin{array}{l}\text { Existência e funcionamento } \\
\text { do FEHIDRO }\end{array}$ & $\begin{array}{l}\text { O FEMAC foi } \\
\text { criado, mas } \\
\text { não está em } \\
\text { operação }\end{array}$ & $\begin{array}{l}\text { Estágio } \\
\text { Básico }\end{array}$ & $\begin{array}{l}\text { O PLERH-AC prevê a } \\
\text { operacionalização do } \\
\text { FEMAC com destinação } \\
\text { de recursos a partir de } \\
2014 \text {, no projeto } 4.3\end{array}$ \\
\hline
\end{tabular}

Fonte: elaborado pelo autor.

\section{1 Planos de Recursos Hídricos}

O plano acreano existe e também há uma estratégia de monitoramento definida para acompanhamento da sua implementação, com um conjunto de 46 indicadores, porém, ainda não existe publicação referente ao monitoramento mencionado. O acompanhamento da implantação desse instrumento é essencial à boa gestão, por isso, a falta de elaboração e/ou publicação de um relatório de situação dos recursos hídricos demonstra que a ferramenta de avaliação e monitoramento não está em uso.

O plano estadual mencionado define as instituições responsáveis pela execução das metas e também define a CMAl como ente responsável pelo monitoramento da implantação deste plano.

Após apresentação das justificativas acima, o termômetro para o plano estadual foi de estágio intermediário. Para subir ao estágio avançado, recomenda-se a institucionalização e o uso da ferramenta de avaliação e monitoramento com publicação periódica do relatório de situação dos recursos hídricos no Acre, incluindo o acompanhamento da relação das ações implementadas com as ações previstas em tal plano.

O fato deste estado amazônico não ter construído nenhum plano de bacia mostra certa dificuldade em adotar a bacia hidrográfica como unidade de planejamento, registrando estágio básico no termômetro, 
em tal quesito. Outros fatores que justificam o estágio selecionado são: a meta prevista no PLERH-AC, que é a de elaborar 30 planos de bacias, para ser cumprida apenas até 2020; a realização da mobilização dos diversos segmentos da bacia para apresentação da proposta de elaboração destes planos foi feita somente em alguns dos igarapés prioritários; e os estudos necessários para viabilizar os planos em questão precisam iniciar.

Recomenda-se priorizar a mobilização dos diversos segmentos para apresentação da proposta de elaboração ou aprovação dos planos de bacia, aproveitando as comissões pró-comitê já criadas, e priorizar também a realização de estudos para viabilizar tais planos nas bacias consideradas estratégicas, as quais foram abordadas anteriormente. Por exemplo, os primeiros planos de bacia deveriam ser trabalhados nas bacias do Igarapé Judia, bacia do Rio Paraná dos Mouras, bacia do Rio Liberdade e bacia do Riozinho do Rôla, onde já existem mobilizações, articulações e propostas de planos.

\subsection{Enquadramento dos Corpos Hídricos}

Em relação a esse instrumento de gestão, o termômetro marcou estágio básico, pois não existem experiências sobre tal instrumento no Acre. Os estudos para implantação do mesmo ainda não iniciaram e a meta de enquadramento de 12 corpos d'água em classes de usos preponderantes, prevista no PLERH-AC, deve ser cumprida até 2020.

\subsection{Sistema de Informações}

Ao abordar tal sistema, o termômetro apontou estágio básico, porque não foram implantadas estruturas interativas e de fácil compreensão, disponibilizadas em ambiente Web, para que haja amplo acesso por parte da população e das instituições, e porque a meta prevista no PLERH-AC era de implantação e funcionamento do SIRENA até o final de 2014 , o que não ocorreu.

De qualquer forma, deve-se reconhecer o avanço no número de estações de monitoramento implantadas nessa unidade da federação, nos últimos anos. 
Propõe-se priorizar o desenvolvimento de ferramentas computacionais e modelos de apoio à decisão; capacitar técnicos das prefeituras municipais e do governo estadual, dos usuários e da sociedade civil para uso do sistema; integrar o sistema estadual com o sistema nacional de informações sobre recursos hídricos; e disponibilizar este sistema em ambiente Web, conforme ações previstas no plano estadual. Para isso, propõe-se ainda a continuidade do convênio existente ou fechamento de novos convênios para ampliação da rede de monitoramento nas UGRHs acreanas.

\subsection{Outorga do Direito de Uso dos Recursos Hídricos}

De acordo com a SEMA (2012), a Resolução CEMACT $n^{\circ}$ 04, de 17 de agosto de 2010, regulamentou a concessão de outorga provisória e de direito de uso dos recursos hídricos no Acre, disciplinando o regime de outorga de direitos de uso dos recursos hídricos de domínio estadual, devendo ser expedida pelo IMAC, e lembrando que o cadastro de usos e usuários para fins de implantação da outorga deve estar integrado ao CNARH, junto à ANA. Entretanto, em consulta ao sítio eletrônico do órgão gestor dos recursos hídricos, tal resolução não está disponível ao público.

Além disso, a meta presente no PLERH-AC é que o sistema de outorga do direito de uso seja implantado e esteja em funcionamento, em todas as UGRHs, até o final de 2020, sendo que precisam ser executadas, ainda, no mínimo seis das sete ações previstas no mesmo, entre elas: (i) confecção de um manual de outorga para a orientação aos usuários; (ii) promoção da integração do sistema de outorga com o sistema de licenciamento ambiental do estado; (iii) cadastro de usos consuntivos e não consuntivos, e dos usuários de recursos hídricos superficiais e subterrâneos; (iv) cadastro de captações e lançamentos industriais; (v) integração ao cadastro, das fontes pontuais potencialmente poluidoras; (vi) integração do sistema de cadastro de usos e usuários do Acre ao CNARH.

Outro argumento relevante é que não foram elaboradas, aprovadas ou disponibilizadas ao público no sítio eletrônico do órgão gestor estadual resoluções do CEMACT contendo encaminhamentos relativos ao sistema de outorga. 
Assim, os argumentos socializados anteriormente demonstram que o termômetro para tal instrumento de gestão indicou estágio básico.

Para elevar tal estágio para intermediário, sugere-se começar e concluir urgentemente o cadastro dos usos e usuários, e o cadastro de captações e lançamentos industriais, disponibilizando-os ao público via sítio eletrônico do órgão gestor estadual, paralelamente à construção, divulgação e orientação para uso do manual de outorga. 


\section{4 Cobrança pelo Uso dos Recursos Hídricos}

Enfatizando-se esse instrumento de gestão, o termômetro registrou estágio básico mais uma vez, já que não existem experiências a respeito do instrumento em questão, e pelo fato dos estudos necessários para sua implantação não terem obedecido o prazo de execução até 2014 , conforme estava previsto no PLERH-AC.

Outra justificativa para o estágio registrado pelo termômetro é que, na prática e na realidade local, a implantação da cobrança nesta unidade da federação está distante, tanto que a previsão do plano estadual é que tal mecanismo seja implementado até 2020.

Recomenda-se, primeiramente, elaborar o cadastro de usos e usuários de recursos hídricos superficiais e subterrâneos, e o cadastro de captações e lançamentos industriais, porque, sem eles, não há como pensar em cobrança. Recomenda-se, também, a conclusão do estudo referente aos instrumentos econômicos de gestão de recursos hídricos adequados ao Acre, com foco na cobrança, entretanto, com a finalidade de integrar políticas públicas, pensando em instrumentos econômicos que utilizem o conceito do provedor-recebedor, por meio de uma possível futura regulamentação do Programa de Incentivos a Serviços Ambientais Hídricos do Sistema Estadual de Incentivos a Serviços Ambientais - SISA.

\subsection{Fundo para Recursos Hídricos}

O termômetro apontou estágio básico pelo fato do FEMAC existir desde a aprovação da política estadual de recursos hídricos e de não ter funcionado com destinação de recursos para gestão dos recursos em pauta.

Acrescenta-se, ainda, que não há resoluções do CEMACT com encaminhamentos pertinentes ao assunto abordado ou elas não estão disponíveis ao público no sítio eletrônico do órgão gestor estadual, apesar da previsão de operacionalização deste fundo a partir de 2014, conforme consta nas metas do PLERH-AC.

Outra meta de tal plano ainda não alcançada está presente no projeto 6.1 , relativo à identificação de fontes de financiamento para o sistema estadual de gerenciamento, a qual prevê dez projetos 
elaborados e aprovados no Plano de Ação do plano mencionado até 2014, o que não se concretizou ou não há resoluções do conselho estadual a respeito de possíveis encaminhamentos.

Assim, no momento, não há clareza sobre o dimensionamento dos recursos e a definição da sua origem, além desses recursos não estarem disponíveis.

A legislação estadual pertinente à política ambiental definiu a origem dos recursos para aplicação na política ambiental e na política de recursos hídricos, porém não dimensionou e não identificou o montante a ser destinado especificamente à gestão dos recursos hídricos. Frisa-se, também, que essa legislação prevê a publicação semestral do quadro demonstrativo das origens e aplicações dos recursos do fundo no Diário Oficial do Estado e em periódico local de grande circulação. Recomenda-se, ainda, a publicação desse quadro demonstrativo no sítio eletrônico do órgão gestor estadual, com o intuito de promover o acesso às informações e garantir transparência no processo, o que não aconteceu ou não acontece.

A indisponibilidade de recursos financeiros por meio desse fundo reflete na falta de operacionalização do sistema estadual e na intensificação das dificuldades de implantação dos instrumentos de gestão, influenciando ainda no interesse de participação, tanto da sociedade civil organizada quanto dos órgãos públicos, pois o CEMACT acaba deliberando ações sem recursos garantidos para posterior execução das mesmas.

Enfim, a regulamentação e operacionalização do FEMAC, bem como a elaboração e conclusão do estudo de sustentabilidade econômico-financeira do modelo de gestão adotado pelo Acre, a identificação de outras fontes de financiamento, a concretização de parcerias para a implementação do sistema estadual e a negociação da inserção de recursos no Plano Plurianual - PPA do Governo do Estado para viabilizar projetos estruturantes na área de recursos hídricos são essenciais para o êxito de tal política.

Em geral, a principal recomendação relativa à dimensão de governança intitulada instrumentos de gestão do sistema no Acre é priorizar investimentos para elaboração dos cadastros, ampliação da rede de monitoramento, implementação e fortalecimento do sistema de informações, uso da ferramenta de avaliação e monitoramento da 
implantação do plano estadual, pois tais ações precedem a implementação dos outros instrumentos - outorga, enquadramento e cobrança.

\section{Conclusão}

$\mathrm{Na}$ dimensão de governança chamada instrumento de gestão do sistema acreano, o termômetro registra estágio básico na gestão dos recursos hídricos pelo somatório da verificação dos indicadores referentes à existência de cadastro atualizado de usos e usuários disponível ao público e à existência da cobrança pelo uso dos recursos hídricos, com os termômetros para cada um dos instrumentos de gestão analisados.

Em relação aos indicadores citados, como o cadastro ainda se encontra em construção e não há experiências pertinentes à cobrança, reforça-se o estágio básico marcado pelo termômetro para a gestão acreana de tais recursos.

\section{REFERÊNCIAS}

ACRE. Lei $N^{0} 1.117$, de 26 de janeiro de 1994, que dispõe sobre a política ambiental do Estado do Acre.

Lei No 1.500, de 15 de julho de 2003, que institui a Política Estadual de Recursos Hídricos, cria o Sistema Estadual de Gerenciamento de Recursos Hídricos do Acre e dispõe sobre infrações e penalidades aplicáveis.

Secretaria de Estado de Planejamento - SEPLAN. Acre em números. Rio Branco: SEPLAN, 2011.

Secretaria de Estado de Meio Ambiente - SEMA. Plano estadual de recursos hídricos do Acre. Rio Branco: SEMA, 2012. 244 p.

AGÊNCIA NACIONAL DE ÁGUAS. Água na medida certa: a hidrometria no Brasil. Agência Nacional de Águas. Brasília: ANA, 2012. 72 p. 
---_-- Conjuntura dos recursos hídricos no Brasil: 2013. Agência Nacional de Águas. Brasília: ANA, 2013. 432 p. ISBN 978-85-88210015-8.

Outorga de direito de uso de recursos hídricos. Agência Nacional de Águas. Brasília: SAG, 2011. 50 p. (Cadernos de capacitação em Recursos Hídricos; v.6). ISBN 978-85-89629-78-2.

Planos de recursos hídricos e enquadramento dos corpos de água. Agência Nacional de Águas. Brasília: SAG, 2011. 100 p. (Cadernos de Capacitação em Recursos Hídricos; v.5).

BRASIL. Lei No 9.433, de 8 de janeiro e 1997, que institui a Política Nacional de Recursos Hídricos, cria o Sistema Nacional de Gerenciamento de Recursos Hídricos, regulamenta o inciso XIX do art. 21 da Constituição Federal, e altera o art. $1^{\circ}$ da Lei No 8.001, de 13 de março de 1990, que modificou a Lei № 7.990, de 28 de dezembro de 1989.

CONSELHO ESTADUAL DE RECURSOS HÍDRICOS DE SÃO PAULO. Deliberação $n^{\circ} 147$, de 11 de dezembro de 2012, que aprova critérios de distribuição dos recursos financeiros do FEHIDRO entre as Unidades de Gerenciamento de Recursos Hídricos a vigorarem a partir do exercício de 2013.

CYMBALISTA, R.; TSUKUMO, I. T. L.; MENEGON, N. M.; BROSE, M. E. Políticas públicas para o centro: controle social do financiamento do BID à Prefeitura Municipal de São Paulo, São Paulo: Instituto Pólis, 2008. 160 p.

DALLABRIDA, V. R. Governança territorial e desenvolvimento: introdução ao tema. In. ROSSETTO, A. M.; BRANDÃO, C. A.; SEGATTO, C. I.; SIEDENBERG, D. R.; COSTA, E. J. M. da; FILIPPIM, E. S.; MUSSOI, E. M.; TENÓRIO, F. G.; ABRUCIO, F. L.; THEIS, I. M.; KORNIN, T.; SOUZA, M. A. de; ROVER, O. J.; MADOERY, O.; VERGARA, P.; BÜTTENBENDER, P. L.; BANDEIRA, P. S.; MOURA, R.; BOISIER, S.; ALLEBRANDT, S. L.; DALLABRIDA, V. R. (Org.); ZIMMERMANN,V. J.; BIRKNER, W. M. K. 
Governança territorial e desenvolvimento: descentralização políticoadministrativa, estruturas subnacionais de gestão do desenvolvimento e capacidades estatais. Rio de Janeiro: Garamond, . p. 15-38, 2011.

ROBLES, G.; FLORIAN, E.; CIFUENTES, M.; LOUMAN, B.; RINGHOLZ, P.; CORNEJO-HÖESL, R. Gobernanza y gestion forestal con énfasis en REDD+: manual didáctico para la formación de capacitadores. CATIE y $\mathrm{GIZ}, 2011$.

SANT'ANNA, F. M. As bacias transfronteiriças da região MAP: cooperação e gestão. In: Encontro Nacional dos Geógrafos, 16., 2010, Porto Alegre. Anais... Porto Alegre: AGB, 2010. p. 1-14.

SÃO PAULO (Estado). Lei No 7.663, de 30 de dezembro de 1991, que estabelece normas de orientação à Política Estadual de Recursos Hídricos, bem como ao Sistema Integrado de Gerenciamento de Recursos Hídricos.

Secretaria de Saneamento e Recursos Hídricos. Resumo situação dos recursos hídricos no estado de São Paulo: ano base 2012. São Paulo: Secretaria de Saneamento e Recursos Hídricos, 2014.

SERAFIM, L. Controle social nas agências reguladoras brasileiras: entre projetos políticos e modelo institucional. A ANEL nos Governos FHC e Lula (1995-2005). Dissertação (Mestrado em Ciência Política). IFCH UNICAMP, Campinas, 2007.

SETTI, A. A; LIMA, J. E. F. W; CHAVES, A. G. M; PEREIRA, I. C. Introdução ao gerenciamento de recursos hídricos. 2. ed. Brasília: ANEEL, 2000. 207 p.

TENÓRIO, F. G. Descentralização político-administrativa, gestão social e participação cidadã. In. -_.- ROSSETTO, A. M.; BRANDÃO, C. A.; SEGATTO, C. I.; SIEDENBERG, D. R.; COSTA, E. J. M. da; FILIPPIM, E. S.; MUSSOI, E. M.; TENÓRIO, F. G.; ABRUCIO, F. L.; THEIS, I. M.; KORNIN, T.; SOUZA, M. A. de; ROVER, O. J.; MADOERY, O.; VERGARA, P.; BÜTTENBENDER, P. L.; BANDEIRA, P. S.; MOURA, R.; BOISIER, S.; 
ALLEBRANDT, S. L.; DALLABRIDA, V. R. (Org.); ZIMMERMANN,V. J.; BIRKNER, W. M. K. Governança territorial e desenvolvimento: descentralização político-administrativa, estruturas subnacionais de gestão do desenvolvimento e capacidades estatais. Rio de Janeiro: Garamond, p. 73-93, 2011.

TUCCI, C. E. M; MENDES, C. A. Avaliação ambiental integrada de bacia hidrográfica. Brasília: MMA, 2006. 302 p. ISBN 85-7738-047-5.

VILLAR, P. C. Governança da água na América Latina. ANA, Itaipu Binacional - BR, FPTI-BR, 2013 (Curso à Distância oferecido no âmbito do Projeto Água: Conhecimento para Gestão).

WWF BRASIL; FÓRUM NACIONAL DE COMITÊS DE BACIAS HIDROGRÁFICAS. Reflexões e dicas para acompanhar a implementação dos sistemas de gestão de recursos hídricos no Brasil. Brasília: WWF Brasil, 2005.

WWF BRASIL; FUNDAÇÃO GETÚLIO VARGAS. Governança dos recursos hídricos: proposta de indicador para acompanhar sua implementação. São Paulo: WWF Brasil e FGV, 2014. ISBN 978-85-86440-85-4. 
Submetido em 15/04/2014

Aprovado em 11/01/2016

Sobre os autores

Ayri Saraiva Rando

Engenheiro Ambiental, Meste em Desenvolvimento Regional pela Universidade Federal do Acre - UFAC e analista ambiental da empresa Floresta Desenvolvimento de Projetos Ltda.

E-mail: ayrirando@gmail.com

\section{Adailton de Sousa Galvão}

Doutor em Geografia pela Universidade de São Paulo-USP, vice coordenador e professor do Programa de Pós-Graduação, Curso de Mestrado em Desenvolvimento Regional da Universidade Federal do Acre.

E-mail: adailton.geo@gmail.com 